\title{
Supply Chain Management Information Systems Survey for Jordanian Companies
}

\author{
Mahmoud Al-Odeh \\ School of Technology, Art \& Design \\ Bemidji State University, Bemidji, MN, USA \\ Corresponding author: Mahmoud.Al-Odeh@bemidjistate.edu \\ Safwan Altarazi \\ Industrial Engineering Department, School of Applied Technical Sciences \\ German Jordanian University, Amman, Jordan \\ E-mail: safwan.altarazi@gju.edu.jo
}

(Received November 12, 2018; Accepted February 18, 2019)

\begin{abstract}
Effective information system (IS) has been one of the key factors that shaped the supply chain management (SCM) developments in the last few decades. The literature on surveying IS in SCM is somehow scarce, particularly in developing countries. The purpose of this study is to investigate the current use and future adoption direction of Supply Chain Management Information Systems (SCMIS) in Jordan. Data from 64 manufacturing and service firms were collected. The results show that i) the overall implementation of SCMIS is very poor, ii) the currently implemented SCMIS, and the expected to implement, are mostly focusing/will focus on separated functions within firms, iii) integration with suppliers' and customers' system, resistance to change from employees, and insufficient vendor support; are the main problems facing the adaptation of SCMIS, and iv) for improving SCM activities; enhanced information provision and closer cooperation between firms and associated governmental agencies are needed. The study is concluded with recommendations for SCM policymakers, firms' managers, and SCMIS vendors.
\end{abstract}

Keywords- Information systems, Supply chain management, Jordan, Survey.

\section{Introduction}

During the past 20 years, supply chain management (SCM) has emerged as one of the major areas for firms to gain a competitive edge. In addition to globalization, outsourcing, and sustainability issues; information technology evolvement has been shaped the supply chain management (SCM) developments. The evolution of the information systems (IS) facilitated by technological advancements has dramatically affected the supply chain (SC) integration, enhance SCM performance, and providing more value to customers. Particularly, many benefits have been achieved by using IS in SCs, including sharing information, generating real-time reports, supporting the process of making accurate prompt decisions, adapting quickly to the market changes, reducing waste and cost, and improving customers' satisfaction (Al-Odeh, 2016).

Whether it is intra-organizational or inter-organizational, an IS is a collection of information technology (IT) resources, including communications networks, hardware IT applications, standards for data transmission, and human skills and experiences (Williamson et al., 2004). There has been a lot of literature indicating the use of intra-organizational IS such as Material Requirements Planning (MRP), Manufacturing Resource Planning (MRPII), Enterprise Resource Planning (ERP), Supplier Relationships Management (SRM), and Customer Relationships Management (CRM) (Ketikidis et al., 2008). Fewer developments in inter-organizational have been 
International Journal of Mathematical, Engineering and Management Sciences

Vol. 4, No. 3, 567-579, 2019

https://dx.doi.org/10.33889/IJMEMS.2019.4.3-045

advanced. Shore (2001) categorized inter-organizational IS developments in four phases: paperbased information flows (e.g. copies of purchase orders), the development of electronic data exchange (EDI), Enterprise-wide systems mainly characterized by Enterprise Resource Planning (ERP), and the systems enabled by the use of web development technologies such as Extensible Markup Language (XML) and Java. Other technologies, such as wireless and mobile technology and Radio Frequency Identification (RFID) have been also implemented in the SCs of different business sectors.

Although it is impossible to achieve an effective supply chain without integrated IS, few literature studies on surveying the IS in SCM can be found (Gunasekaran and Ngai, 2004). Literature scarcity becomes worse for developing countries. This research aims to explore the current use and future adoption direction of IS for SCM in Jordan, accordingly, provides guidelines to policymakers and firms' managers for better-fitted policies and resources allocation. As a predecessor step for surveying Supply Chain Management Information Systems (SCMIS), the adoptions of common SCM strategies within the surveyed companies are investigated.

The paper is organized as follows. First, previous SCM-related studies conducted in Jordan are reviewed. Then, the research methodology and the characteristics of the responding firms are discussed. Section four presents the research findings while section five discusses these findings. Finally, section six provides some concluding remarks and recommendations.

\section{SCM Previous Studies in Jordan}

Limited literature can be found with respect to SCM activities in Jordan. Although it is possible to summarize this research work in chronological order, it was selected to present it according to the studied subject, detailing the approach adopted and the major findings.

Al-Ma'aitah (2014) studied the cultural perspective in supply chain relationships within the Jordanian manufacturing sector. The study examined eastern Arab cultural values and their impacts on the long-term relationships between buyer and supplier. A quantitative survey methodology of two samples including 350 buyers and 302 suppliers, were conducted in this study. Six main values were investigated (to know someone, networking, promise, fatalism, face-saving, and consultative). The results show that the medium to strong relationship exists between the studied values and longterm buyer-supplier relationship.

Abdallah et al. (2014) conducted a study to investigate the impact of SCM practices on supply chain performance by surveying 104 Jordanian manufacturing companies. The researchers found that three management practices impacted the efficiency of a SC, namely: internal integration, information sharing, and postponement. Surprisingly, the supplier integration and customer integration were found insignificant with regard to the performance of SC in Jordan. With respect to SCM-financial performance for companies, Salhieh (2011) studied the relationship between SCM practices and organizational financial performance. There are 28 manufacturing companies registered in the first market of the Amman Stock Exchange participated in the study. Regression analysis results indicated a strong relationship between SCM practices companies and bottom-line profits. In another SC-performance related research, Al-Saa'da et al. (2013) conducted a study to measure the effect of SCM dimensions on the quality of healthcare services dimensions in private hospitals in Jordan. The study analyzed 315 questionnaire responses collected from employees working in the departments of supply and procurement in 36 Jordanian private hospitals. The study 
International Journal of Mathematical, Engineering and Management Sciences

Vol. 4, No. 3, 567-579, 2019

https://dx.doi.org/10.33889/IJMEMS.2019.4.3-045

results showed a significant relationship between the SCM dimensions and relationship with suppliers, specifications and standards, after-sales service; and the quality of health services.

Recently, Green SCM (GSCM) has attracted some of the Jordanian researchers' attention. In their work, Hijaz et al. (2015) evaluated the current state of the Jordanian marketplace in the context of GSCM aspects including product delivery time, currency exchange, the use of IS for data sharing, tax increments, and indecent competition. Based on interviews with a sample of small-to-medium enterprises (SMEs) the study found a high deficiency in all GSCM aspects and concluded that SMEs in Jordan have minimal attention towards the environment. Al Khattab et al. (2015) examined the GSCM impact on the performance of environmental-based marketing. Through questioning top and middle managerial levels in five Jordanian companies, the statistical analysis of the results showed that the significant GSCM practices which affect the environmental-based marketing performance are: internal environmental management, green purchasing, green IS, cooperation with customers, eco-design and packaging, and investment recovery. Focusing on Jordanian food production companies, Zu'bi et al. (2015) implemented descriptive and inferential statistical tools to investigate the effects of supply chain integration on environmental performance. The results of the study indicated that supply chain integration can positively affect environmental performance, control, and pollution management.

Jraisat (2010) developed and examined a conceptual framework that explains factors of the export supply chain relationship, for fresh fruit and vegetables between Jordan and the European Union, with focusing on information sharing. Based on expert interviews and ten case studies analyses, the study found that companies can gain strategic advantages from SCM based on the information; thus, improve their financial and non-financial export performance. Al-Odeh (2010) investigated the state of SCM and the use of information systems to support it at Al-Hassan Industrial Estate in Jordan. Through interviewing 49 companies, the study mainly found Jordanian companies are focusing on developing relationships with suppliers more than customers.

As can be seen from the above literature survey, no previous research was conducted to examine the implemented strategies and information systems for SCM in Jordan. This research aims to cover this gap.

\section{Research Methodology}

Combinations of different methodologies were used in this study: literature review, questionnaire survey, and interviews (by phone and over the Internet). Studying previous literature helped the researchers understand the different information systems (IS) that are used for SCM and to design an online questionnaire to gather data from firms on issues related to the current situation, challenges, benefits, and development of SCMIS in Jordan. The study surveyed 64 out of 170 companies from the manufacturing and service sectors. The researchers sent the survey to operations, supply chain, and/or technology managers of those companies to partake in the study. An email with a link for the survey is sent to 170 managers and then followed up with a phone call to confirm receipt within two days. This practice encouraged managers to participate in the study and take it while they are on the phone. The sample is identified by performing a google search with "List of Companies in Jordan" as the key phrase. The participants voluntarily participated in the study. The data collected and the conclusions from these interviews are explained in the following section. 
Figure 1(a) shows the sectors of the participated companies while Figure 1(b) shows their size. As can be seen, the focus (58\%) was on companies from the service sector. This emphasis is justified since about $59 \%$ of the Jordanian gross domestic product (GDP) is generated by the service sector, agriculture contributed around $4 \%$, and $25.43 \%$ came from the manufacturing and industry sector (The World Bank, 2013) (Jordan Chamber of Industry, 2014) (statista.com, 2017). Similarly, since the majority of Jordanian firms are in the small-to-medium size range (Al-Mahrouq, 2010), the majority (68.75\%) of participated companies fits under this category (had less than 500 employees).

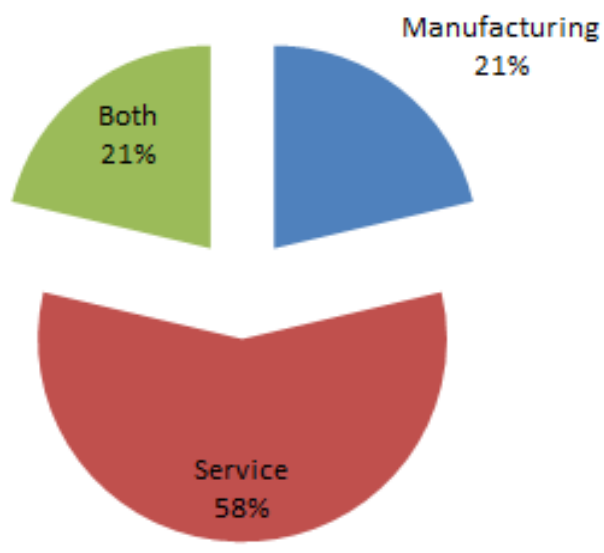

(a) The participated companies profile

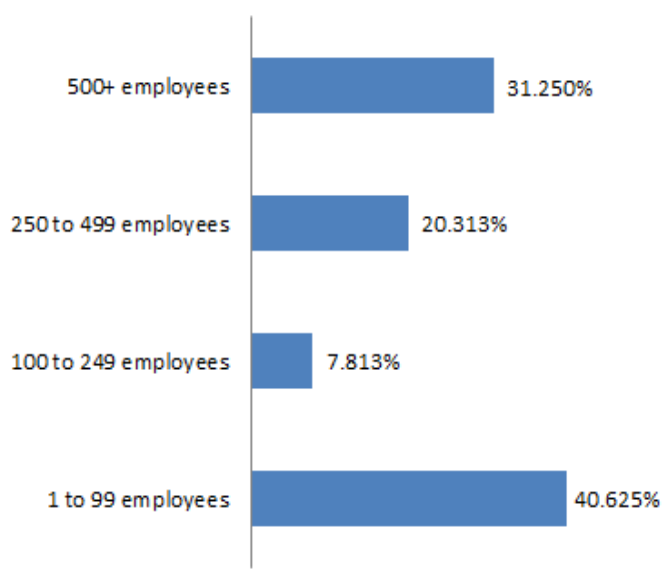

(b) The size of the participated companies

Figure 1. Surveyed companies' background

The questionnaire consists of 17 closed questions built based on best practices from literature and industry. A pilot survey was conducted as a validation strategy to ensure that the research objectives can be achieved through the questions used in the questionnaire. Three companies were randomly chosen for this refinement process. The questionnaire was updated regarding recommendations from the participants of the pilot survey. About 15 minutes were needed to finish the questionnaire that consists of four parts: The first part aimed to identify the profile of the companies who participated in the study. The second part investigated the surveyed companies' background regarding SCM. The third part of focused on the current SCMIS used by surveyed companies. Finally, the last part of the survey was designed to investigate the 2-year future of SCMIS adoption in Jordan.

After collecting the data, the SPSS software was used to analyze it. Mainly, descriptive analysis was conducted and figures were used to give a better understanding of the results.

\section{Research Findings}

The survey's data analysis showed interesting findings in significant issues related to the objective of this study. These findings are classified into three succeeding subsections and summarized in a later subsection. 
International Journal of Mathematical, Engineering and Management Sciences

Vol. 4, No. 3, 567-579, 2019

https://dx.doi.org/10.33889/IJMEMS.2019.4.3-045

\subsection{SCM Background in the Companies}

This part of the survey described the SCM background of the surveyed firms including SCM within the firms' structure, adopted SCM strategies, evaluating logistical customer service, and the success rate of implementing SCM activities.

As indicated by Figure 2, the results indicated that $61 \%$ of the surveyed firms have separate SCM/logistics departments. Interestingly, very close percent $(59 \%)$ of survey participants (operations and technology managers) believed that their companies SCM/logistics strategic plan is clear.

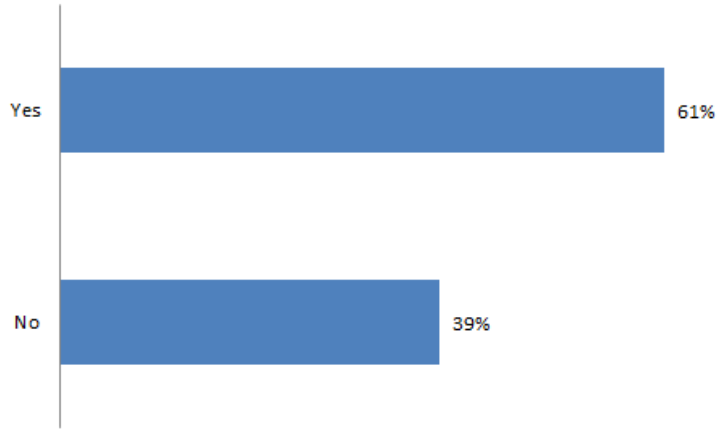

(a) Separate SCM department

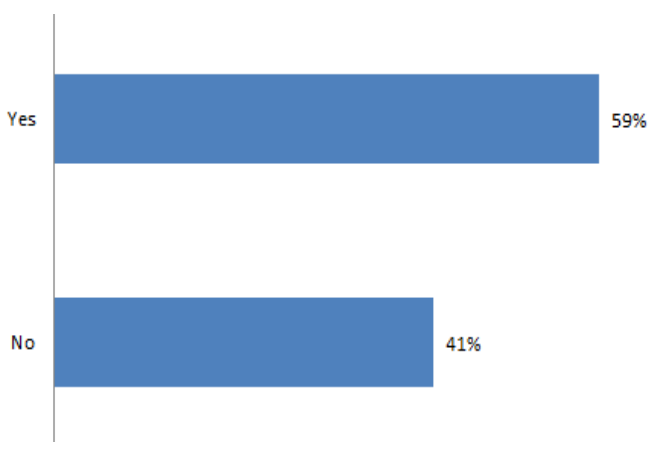

(b) The clarity of SCM strategic plan

Figure 2. SCM in companies' structure and strategies

Figure 3 summarizes the questions' answers about evaluating logistical customer service. Total cycle time, customer feedback, and percent of correctly delivered products/services were the most popular utilized methods for measuring logistical customer service in Jordan. Products availability and tracking came next but with roughly comparable scores. This result is, in fact, encouraging as it implies that logistical customer service, as acknowledged from the customers' perspective, can be significantly improved by adopting better appropriate SCMIS.

As a part of companies' background, the survey tried to uncover which SCM strategies Jordanian companies find keen to manage their supply chain. Although neither single nor group of strategies gained an overwhelming score, Figure 4 indicates that the main three strategies adopted were a close partnerships with suppliers, close partnership with customers, and holding safety stock.

Finally, this part of the survey asked about the success in managing Jordanian SCs and the companies' satisfaction regarding current public policies. As given by Figure 5(a), only about half of the surveyed companies were found successful or highly successful in managing their SC. The success in managing SC is measured based on these factors: inventory turnover \& accuracy, delivery/shipment times, and warranty costs as a percentage of sales. Interestingly, more than $78 \%$ of the companies were neutral or worse with respect to their satisfaction with the current public SCM-related policies (Figure 5(b)). The public SCM-related policies are policies and guidelines established by the government authorities to regulate the activates in the SCM sector. These results imply a motivating opportunity for improved SCM activities and policies, and whom better than SCMIS to support achieving this target. 
International Journal of Mathematical, Engineering and Management Sciences

Vol. 4, No. 3, 567-579, 2019

https://dx.doi.org/10.33889/IJMEMS.2019.4.3-045

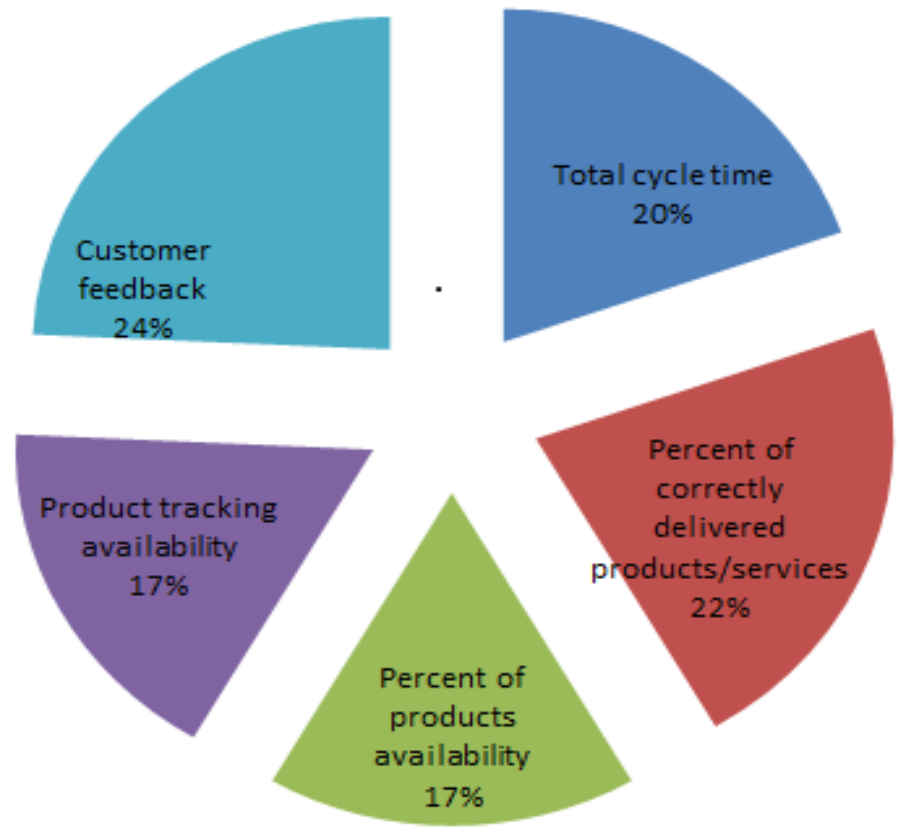

Figure 3. Strategies used for evaluating logistic customer service

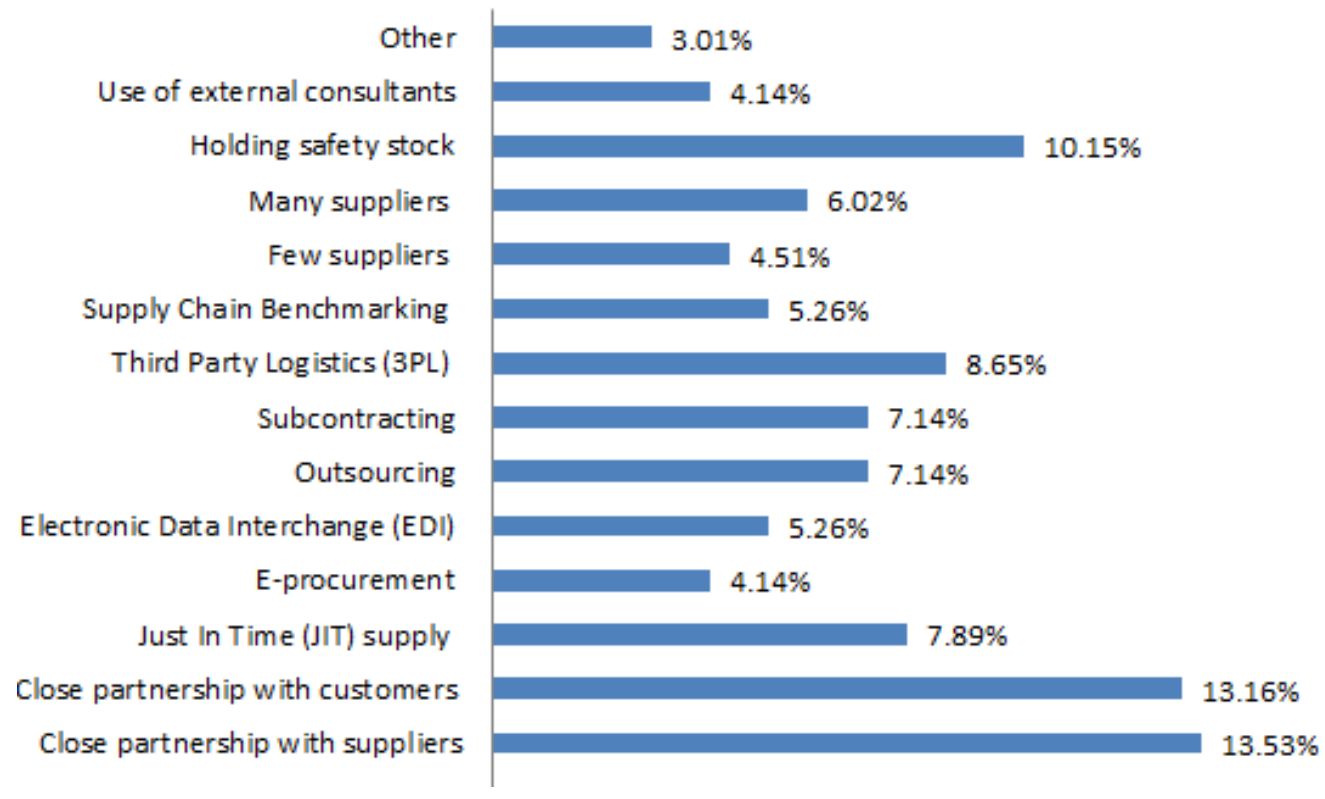

Figure 4. Current implemented SCM Strategies 
International Journal of Mathematical, Engineering and Management Sciences

Vol. 4, No. 3, 567-579, 2019

https://dx.doi.org/10.33889/IJMEMS.2019.4.3-045

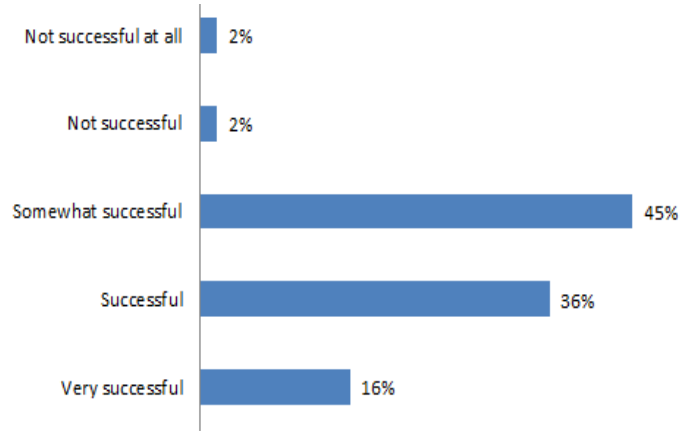

(a) The success of managing $\mathrm{SC}$

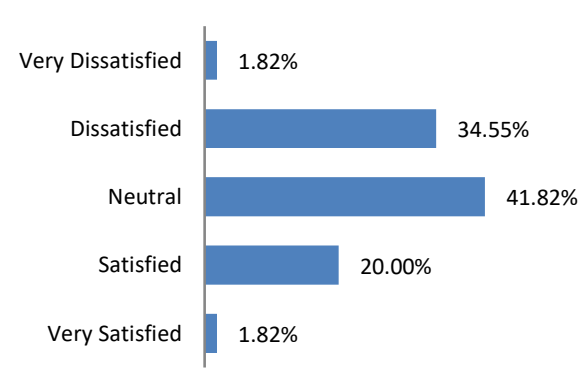

(b) Satisfaction with current SCM public policies

Figure 5. SCM activities and public policies performance

\subsection{Current Use of SCMIS}

This part of the analysis focuses on the current situation of the SCMIS in Jordan. The issues which looked after here were the current use of SCMIS, its' benefits, and problems faced. Figure 6 depicts the most popular IS that are currently in use by Jordanian companies to manage their SCs. MRP systems, WMS, CRM systems, and ERP systems; were found the most usable systems. Surveyed managers indicated that the following criteria were dramatically enhanced by implementing SCMIS: inventory level, accurate costing, operational efficiency, and quantity of information. Other performance criteria were improved but with less achievement as summarized in Figure 7. Finally, as illustrated by Figure 8, the most significant problems that rose when implementing new SCMIS were: change resistance by employees, integration with existing systems, and insufficient vendor support.

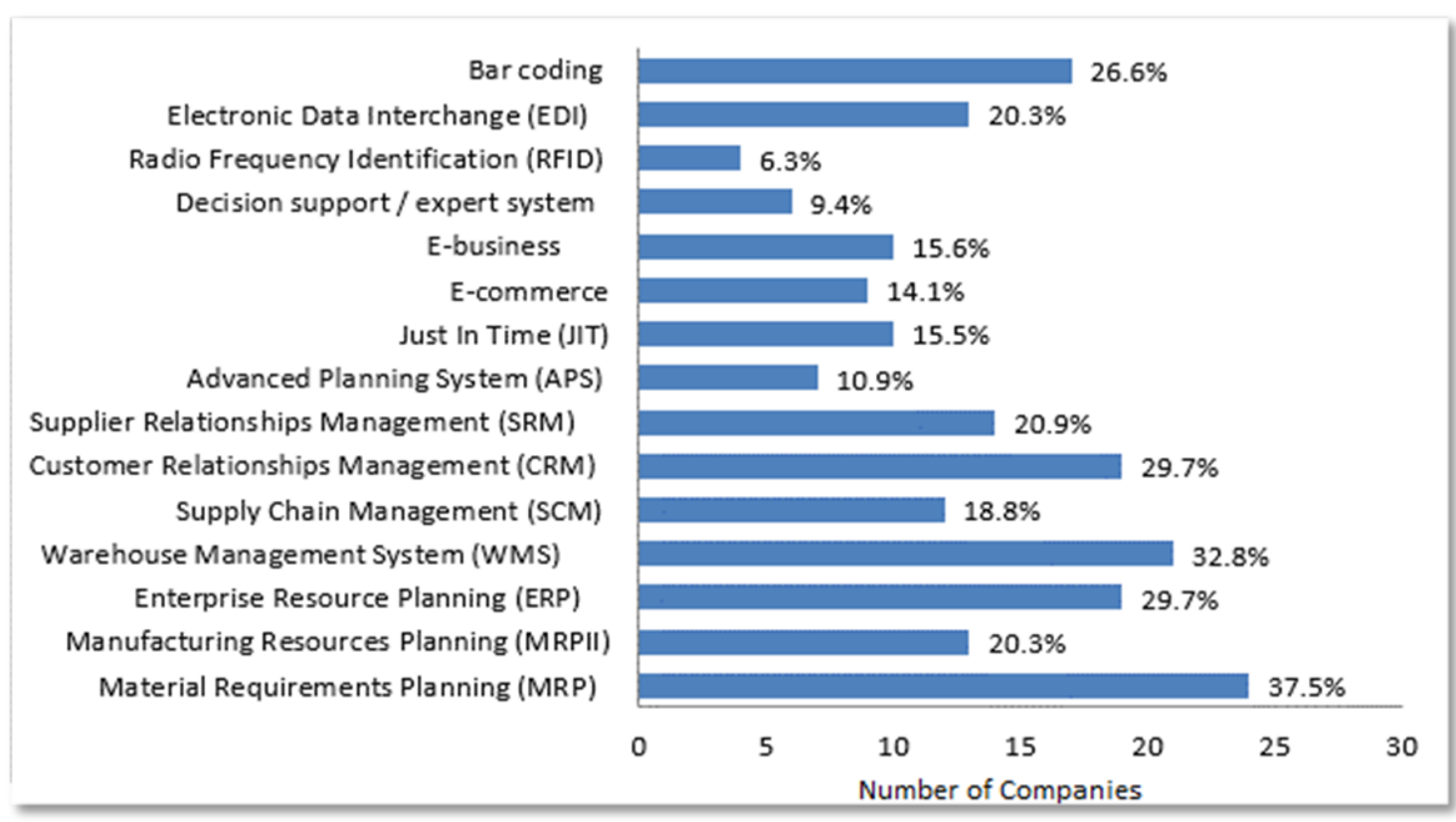

Figure 6. Current use of SCMIS 
International Journal of Mathematical, Engineering and Management Sciences

Vol. 4, No. 3, 567-579, 2019

https://dx.doi.org/10.33889/IJMEMS.2019.4.3-045

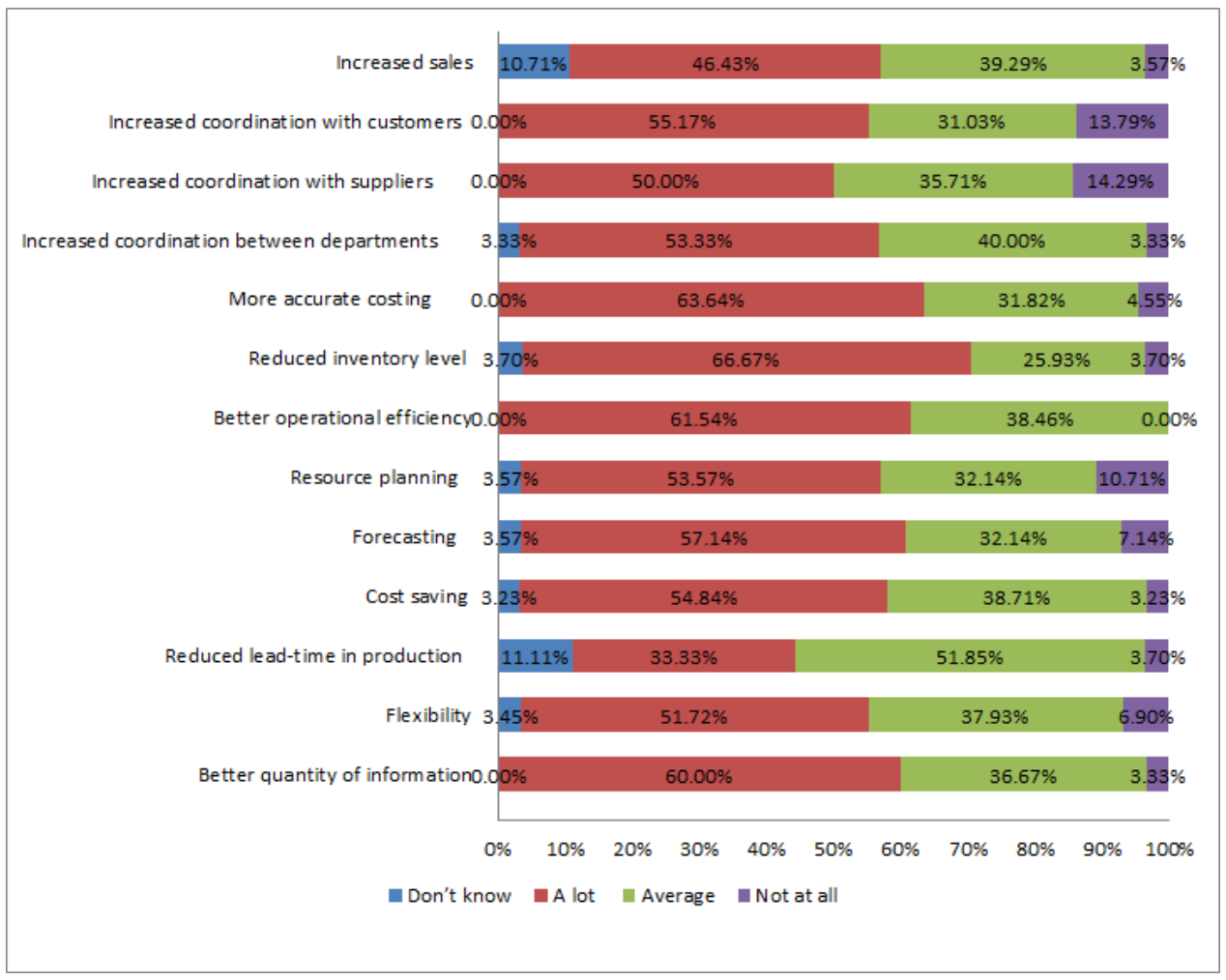

Figure 7. The benefits of using the SCMIS

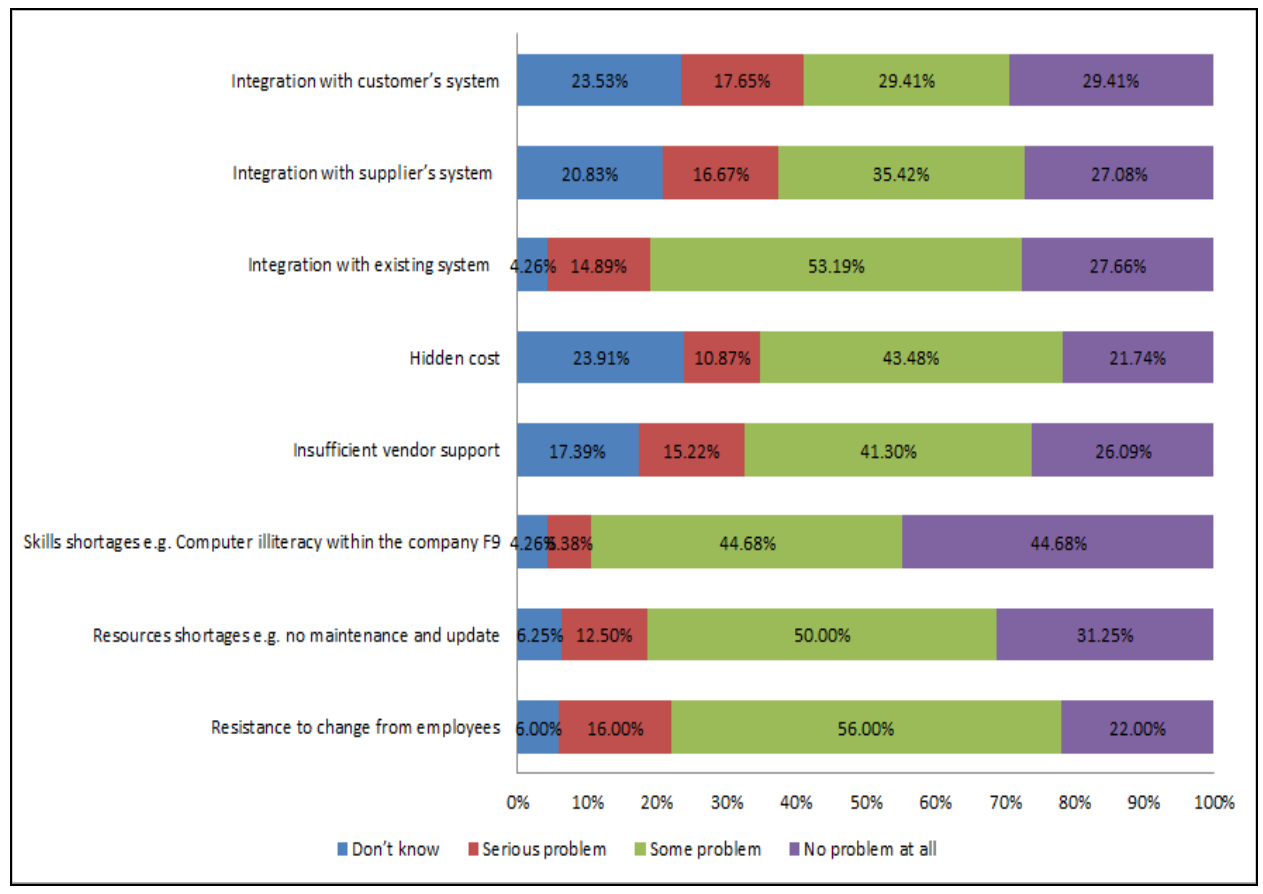

Figure 8. The problems of using SCMIS 
International Journal of Mathematical, Engineering and Management Sciences

Vol. 4, No. 3, 567-579, 2019

https://dx.doi.org/10.33889/IJMEMS.2019.4.3-045

\subsection{Future Direction of SCMIS}

Two issues were surveyed regarding the future of SCMIS in Jordan: what SCMIS Jordanian companies are planning to implement within the next two years, and required strategies which are necessary for SCM improvement and the relationship of these strategies with IS. Regarding the first issue, as depicted by Figure 9, it was found that the main SCMIS are: MRP, SCM benchmarking, ERP, and WMS. RFID and E-commerce systems attracted the least implementation intention. For the future SCM-strategies requirement issue, the surveyed companies believed that improved information provision, and closer cooperation between companies and government are the most important strategies which need to be advanced for pushing SCM activities. Interestingly, both of these strategies are IS related. Other strategies such as improved cooperation with the chamber of commerce and better education and training came next. Figure 10 summarizes the results of this issue.

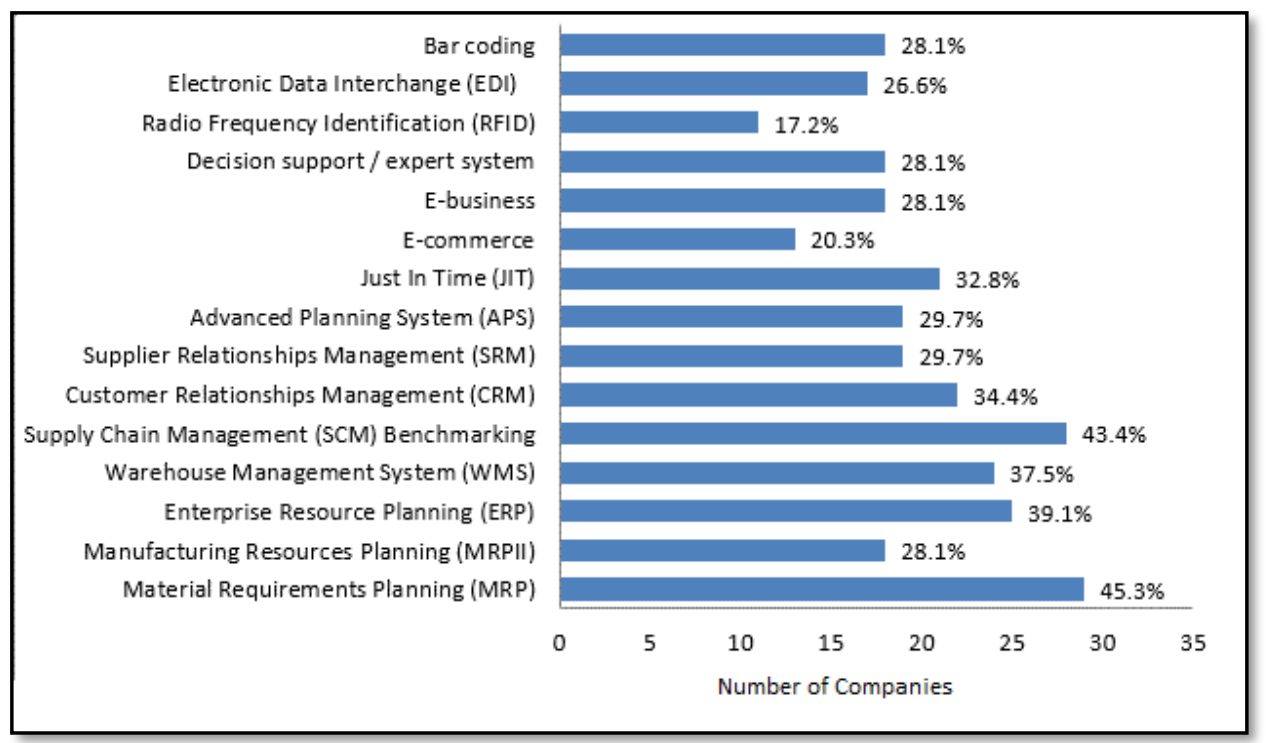

Figure 9. What SCMIS companies will implement within the next two years

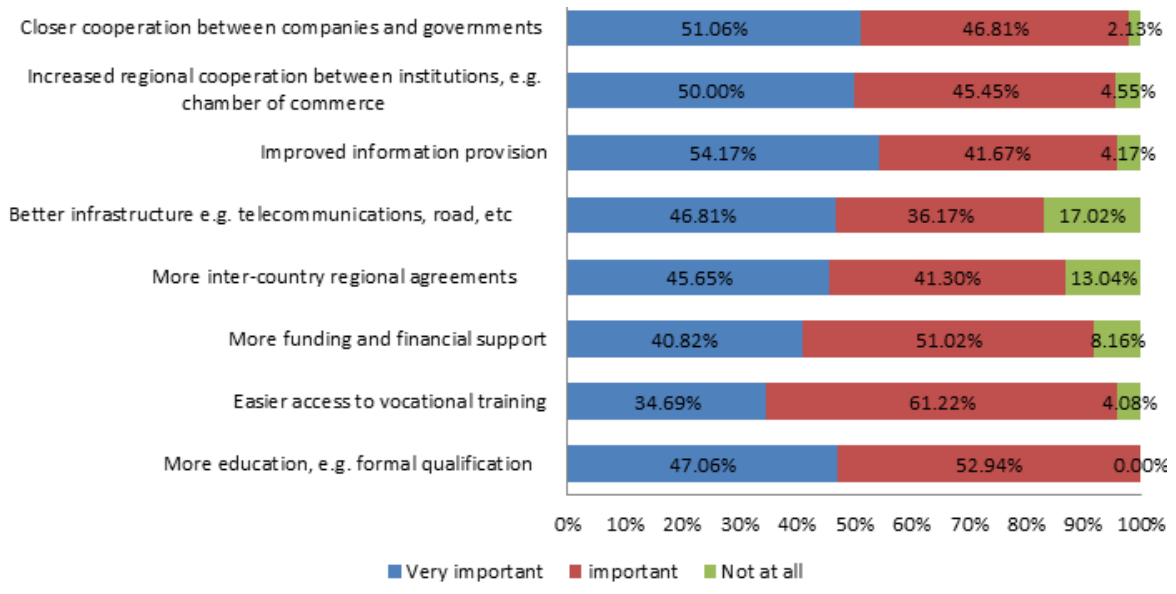

Figure 10. Strategies to improve the future of SCM 
International Journal of Mathematical, Engineering and Management Sciences

Vol. 4, No. 3, 567-579, 2019

https://dx.doi.org/10.33889/IJMEMS.2019.4.3-045

\subsection{Summary of the Findings}

This section summarizes the findings of the current study in the following points:

- The majority the firms have separate logistics department, consequently, SCM strategic plan was clear for the majority of companies.

- The most popular methods for measuring logistical customer service are total cycle time, customer feedback, and percent of correctly delivered products/services.

- Developing a better relationship with suppliers, with customers, and holding safety stock; are the key SCM strategies which Jordanian firms are currently implemented.

- Motivating opportunities exist for improved SCM activities and policies since the majority of the survey answers showed dissatisfaction with current SCM activities in companies and SCM governmental policies.

- The implementation of SCMIS (mainly MRP, WMS, CRM, and ERP) significantly enhanced inventory level estimation, accurate costing, operational efficiency, and quantity of information.

- The following are serious problems facing the implementation of SCMIS: integration with suppliers' and customers' system, resistance to change from employees, and insufficient vendor support.

- The SCMIS which are expected to be implemented in the new future are: MRP, SCM benchmarking, ERP, and WMS.

- Improved information provision and closer cooperation between companies and government are the most important strategies which need to be advanced for improving SCM activities in Jordan.

\section{Findings' Discussion}

It was encouraging to discover that about $60 \%$ of the surveyed managers had a clear picture of the SCM strategic plan in their companies. Unfortunately, this was not totally reflected in the SCM success rate which was just about 50\%. This result can be explained by, although respectively it was among the most implemented SCM strategies, the poor relationships with the suppliers and customers (only about $13 \%$ have a close partnership with suppliers or customers). Additionally, the deficiency of public SCM-related policies and the shortage of professional related training are certainly major reasons for the low success in implementing SCM activities and in achieving its objectives. In fact, better SCM employee training can help in reducing the problems which may be faced in implementing SCMIS as resistance by employees and integration with existing systems.

The findings analysis indicated that most of the currently implemented SCMIS, and the expected to implement, are focusing/will focus on discrete processes or functions within the company walls (such as MRP, WMS, and ERP); few are targeting/will target customers' relationship (such as CRM and E-commerce), or suppliers' relationships (such as SRM), or both (such as EDI and RFID). Generally, focusing on SCM activities within a company more than on relationships with customer, suppliers, or both; is a normal practice [Ballou book] for immature SCs. In the Jordanian case, this helped the companies, and not the supply chains, mainly in improving their inventory managing, products' costing, and operations' efficiency. However, as numbers indicated the implementation percentages of SCMIS in the Jordanian companies are clearly insufficient in all levels: the company level and the collaboration with customers and suppliers level.

Few disturbing findings were discovered from the results analysis. For instance, the very low number of companies who are currently implementing strategies of 3PL, outsourcing, and 
International Journal of Mathematical, Engineering and Management Sciences

Vol. 4, No. 3, 567-579, 2019

https://dx.doi.org/10.33889/IJMEMS.2019.4.3-045

subcontracting indicates the unconsciousness regarding the importance of such strategies (according to Ketikidis et al. (2008), 3PL strategy is one of the most important strategies that are used in both local and international supply networks around the world). Similarly, RFID technology was found to be the least popular SCMIS; only 7 companies are currently implanting it while 11 are planning to implement it within the next 2-year period.

Many findings from the current study pointed on the need for implementing new and/or improving current SCMIS. For example, better SCMIS can help in refining most of the criteria, which are currently adopted to evaluate logistical customer services such as total cycle time products' availability and tracking. Additionally, SCMIS can significantly support achieving future-required SCM strategies: improved information provision, closer cooperation between companies, and government.

\section{Conclusions and Recommendations}

The current study explores for Jordanian firms 1) the current SCM strategies implemented with its implementation satisfaction level, 2) the currently utilized SCMIS with attained benefits and encountered challenges, and 3) the future need for effective SCMIS and SCM policies. Although with low percentages, establishing good relationships with suppliers and customers, and holding safety stock; were found the most adoptable SCM strategies. On the other hand, MRP, WMS, CRM, and ERP; were the most utilized SCMIS. The near future is not expected to see much change in the adaptation of new SCMIS. Regarding the problems facing the implementation of SCMIS, integration with suppliers' and customers' system, resistance to change from employees, and insufficient vendor support; were found most severe.

The following recommendations can be attained as a result of the current study:

- For SCM policymakers: increase awareness in benefits of strategic relationships with supplier and customer, 3PL, and outsourcing, and subcontracting;

- For firms' managers: implement SCMIS that facilitates information sharing and coordination between various echelons in the SC, provide employee training on SCMIS issues, and improve SCM activities.

- For SCMIS vendors: improve your after-sale support, and educate middle and lower management levels regarding the benefits of SCMIS.

\section{Conflict of Interest}

The authors confirm that there no conflict of interest to declare for this publication.

\section{Acknowledgement}

The authors would like to acknowledge and thank the companies and managers who contributed to this research. Thank you for their support and time. The authors are also grateful to the colleagues who reviewed this paper and provided valuable suggestions towards improving it. 
International Journal of Mathematical, Engineering and Management Sciences

Vol. 4, No. 3, 567-579, 2019

https://dx.doi.org/10.33889/IJMEMS.2019.4.3-045

\section{References}

Abdallah, A. B., Obeidat, B. Y., \& Aqqad, N. O. (2014). The impact of supply chain management practices on supply chain performance in Jordan: the moderating effect of competitive intensity. International Business Research, 7(3), 13-27.

Al Khattab, S. A., Abu-Rumman, A. H., \& Massad, M. M. (2015). The impact of the green supply chain management on environmental-based marketing performance. Journal of Service Science and Management, 8(4), 588-597.

Al-Ma'aitah, N. (2014). An examination of supply chain relationships in Jordanian manufacturing context: a cultural perspective (Doctoral dissertation, PhD Thesis, The University of Kent).

Al-Mahrouq, M. (2010). Success factors of small and medium enterprises: the case of Jordan. Zagreb International Review of Economics \& Business, 13(2), 89-106.

Al-Odeh, M. (2011). The current situation of supply chain management and technology structure at AlHassan Industrial Estate in Jordan (Doctoral dissertation). Terre Haute, IN: Indiana State University .

Al-Odeh, M. (2016). Supply Chain Information Systems Technologies and Management Strategies in Northern Minnesota. Journal of Supply Chain Management Systems, 5(2), 22-37.

Al-Saa'da, R. J., Taleb, Y. K. A., Al Abdallat, M. E., Al-Mahasneh, R. A. A., Nimer, N. A., \& Al-Weshah, G. A. (2013). Supply chain management and its effect on health care service quality: quantitative evidence from Jordanian private hospitals. Journal of Management and Strategy, 4(2), 42-51.

Gunasekaran, A., \& Ngai, E. W. (2004). Information systems in supply chain integration and management. European Journal of Operational Research, 159(2), 269-295.

Hijaz, S., Al-Hujran, O., Al-Debei, M. M., \& Abu-Khajil, N. (2015). Green supply chain management and SMEs: a qualitative study. International Journal of Business Information Systems, 18(2), 198-220.

Jraisat, L. E. (2010). Information sharing in an export supply chain relationship: the case of the Jordanian fresh fruit and vegetable export industry (Doctoral dissertation, Brunel University Brunel Business School PhD Theses).

Ketikidis, P. H., Koh, S. C. L., Dimitriadis, N., Gunasekaran, A., \& Kehajova, M. (2008). The use of information systems for logistics and supply chain management in South East Europe: Current status and future direction. Omega, 36(4), 592-599.

Salhieh, L. (2011). An exploratory study of the relationship between supply chain management practices and technical efficiency of Jordanian manufacturing companies. International Journal of Business and Management, 6(12), 126-134.

Shore, B. (2001). Information sharing in global supply chain systems. Journal of Global Information Technology Management, 4(3), 27-50.

Williamson, E. A., Harrison, D. K., \& Jordan, M. (2004). Information systems development within supply chain management. International Journal of Information Management, 24(5), 375-385.

Zu'bi, M. F., Tarawneh, E., Abdallah, A. B., \& Fidawi, M. A. (2015). Investigating supply chain integration effects on environmental performance in the Jordanian food industry. American Journal of Operations Research, 5(4), 247-257.

\section{Links/Websites}

Jordan Chamber of Industry (2014). Developments of the Jordanian economy and the performance of the industrial sector during the year 2014. Amman- Jordan: Jordan Chamber of Industry. Retrieved from http://www.jci.org.jo/EchoBusV3.0/SystemAssets/PDF/AR/JoEconomy2014.pdf 
International Journal of Mathematical, Engineering and Management Sciences

Vol. 4, No. 3, 567-579, 2019

https://dx.doi.org/10.33889/IJMEMS.2019.4.3-045

The World Bank. (2013). Jordan Economic Monitor. The World Bank. Retrieved from http://www.worldbank.org/content/dam/Worldbank/document/MNA/Jordan_EM_Spring_2013.pdf

statista.com. (2019, Feb 9). Jordan: Distribution of gross domestic product (GDP) across economic sectors from 2007 to 2017. Retrieved from statista: https://www.statista.com/statistics/385505/jordan-gdpdistribution-across-economic-sectors/ 